\title{
Letramento acadêmico em francês: uma experiência de produção de artigos científicos na área de estudos literários
}

Academic literacy in french: an experience of production of papers in the area of literary studies

\author{
Eliane Gouvêa LousADA (DLM-FFLCH-USP) \\ Jaci Brasil ToNeLI (DLM-FFLCH-USP) \\ Mariana Casemiro BARIONI (DLM-FFLCH-USP)
}

RESUMO

Neste artigo, temos por objetivo apresentar o modelo didático do gênero textual artigo cientifico em francês para, em seguida, mostrar uma sequência didática elaborada para ensinar a produzir esse gênero assim como reflexões sobre sua aplicação. Para desenvolver as atividades, apoiamo-nos nos conceitos do Interacionismo Sociodiscursivo (Bronckart 1999/2003; Schneuwly e Dolz 2004), que tem como base os escritos de Vigotski (1997,1998). O modelo didático e a sequência foram produzidos como parte de uma experiência piloto promovida pelo Laboratório de Letramento Acadêmico da universidade que visava ao ensino da produção de artigos científicos em língua francesa para alunos da Graduação em Letras.

Palavras-chave: Artigo científico; Interacionismo Sociodiscursivo; Letramento acadêmico; Francês como língua estrangeira. 


\section{ABSTRACT}

In this article, we aim to present the didactic model of the text genre scientific paper in French and, then, show the didactic sequence designed to teach how to write this genre. The activities were based on the concepts of the Socio-discursive Interactionism (Bronckart 1999/2003), which relies on the Vygotskian theoretical framework. The didactic model and the didactic sequence were produced as part of a pilot study that suggested the use of the didactic sequence in order to teach how to write papers in French to Undergraduate students that were enrolled in a French Literature course. This experience was conducted within a partnership with the Laboratory of Academic Literacy.

Key-words: Scientific paper; Socio-discursive interactionism; Academic literacy; French as a second language.

\section{Introdução}

O movimento em direção à internacionalização das universidades brasileiras pode ser evidenciado pela criação de projetos de bolsas de estudo, como, por exemplo, em nível nacional, o programa Ciências Sem Fronteiras e, também, por estímulos à participação em eventos e reuniões internacionais. Um outro exemplo é o Programa de Apoio à Internacionalização da Graduação (Pró-Int), da USP, que destina recursos a estudantes da graduação que participam de eventos ou atividades acadêmicas no exterior.

Nesse contexto, o conhecimento de línguas estrangeiras é de grande importância, pois permite a participação em atividades acadêmicas de âmbito internacional. No entanto, não se trata apenas do domínio da língua: tanto pesquisadores experientes quanto graduandos, mestrandos e doutorandos têm necessidade de conhecer os textos (orais, como a apresentação de comunicação, e escritos, como o resumo para apresentação em congressos ou artigo científico) que circulam na esfera acadêmica para poder participar de atividades internacionais. Embora, na esfera científica, o inglês tenha um papel preponderante, consideramos que a língua francesa é também um canal importante para divulgação de pesquisas brasileiras em âmbito internacional, como têm demonstrado diversos pesquisadores, dentre os quais Dion (2012) e Muller et al. (2012), que defendem o plurilinguismo na ciência. A im- 
portância de nosso estudo sobre a escrita acadêmica em francês também se justifica na área à qual nos filiamos, ou seja o ensino-aprendizagem, ou a Didática do $\mathrm{FLE}^{1}$. Portanto, no atual contexto de internacionalização das universidades e da pesquisa científica em geral, o ensino de gêneros textuais pertencentes à esfera acadêmica em francês ganha significado, pois é necessário que não apenas os pesquisadores, mas também "os alunos aprendam a produzir tanto gêneros orais quanto gêneros escritos para que possam estudar em outros países" (Lousada, Rocha e Guimarães-Santos 2015: 322), ou para que possam participar de atividades acadêmicas em outros países.

Dentre os inúmeros gêneros textuais presentes na esfera acadêmica, como, por exemplo, a comunicação oral em congresso, o resumo, o artigo científico, o plano de estudos (Silva e Lousada 2014), o projeto de pesquisa etc., neste estudo, optamos por focalizar o gênero artigo científico, pois, de acordo com Motta-Roth e Hendges (2010), ele possui alto prestígio no meio universitário. Os artigos publicados em periódicos (nacionais ou internacionais) “correspondem ao gênero mais usado atualmente na academia como meio de produção e divulgação de conhecimento gerado na atividade de pesquisa." (Motta-Roth e Hendges 2010: 23). Por isso, propor formas de ensinar as características marcantes esse gênero, em língua francesa, é de vital importância para inserção de pesquisadores brasileiros no cenário mundial. Sendo assim, temos por objetivo apresentar, primeiramente, o modelo didático (MD) do gênero textual artigo científico em francês e, em seguida, mostrar a sequência didática (SD) elaborada para ensinar a produzir esse gênero. $\mathrm{O}$ pano de fundo que deu origem ao modelo didático e à sequência didática foi uma experiência piloto ${ }^{2}$ de aplicação de atividades didáticas com vistas a ensinar a produzir artigos científicos em língua francesa para alunos da Gradução em Letras-francês, que cursavam, na época, uma disciplina de Literatura (Monografia), cuja exigência era justamente essa. Sendo assim, mostraremos o modelo didático do artigo científico em francês, apresentaremos algumas atividades que compuseram nossa sequência didática e, finalmente, teceremos algumas considerações sobre a aplicação do projeto piloto.

1. Francês como Língua Estrangeira.

2. Essa experiência foi realizada na Faculdade de Filosofia, Letras e Ciências Humanas da USP, no segundo semestre de 2013, e está ligada ao Laboratório de Letramento Acadêmico. 


\section{Pressupostos teóricos e metodológicos}

Para atingir nossos objetivos, apoiamo-nos no Interacionismo Sociodiscursivo (Bronckart 1999/2003, 2006, 2008), uma corrente do Interacionismo Social que adota seus princípios fundadores estabelecidos, sobretudo, a partir da obra de Vigotski $(1997,1998)$. O Interacionismo Sociodiscursivo (ISD) pretende realizar apenas uma parte do projeto do Interacionismo Social, visando a mostrar o papel fundador da linguagem e do funcionamento da atividade discursiva no desenvolvimento humano (Bronckart 1999/2003, 2006, 2008). Para o ISD, as atividades de linguagem desempenham um papel central, sendo elas que conduzem o pensamento humano na direção de um pensamento consciente (Machado 2000). Essa é uma das motivações para a adoção desse quadro teórico quando se trabalha com a escrita acadêmica, já que podemos pensar em uma correlação entre o pensamento e a linguagem, que são cruciais na pesquisa e na escrita sobre a pesquisa. Portanto, nessa perspectiva, o problema da linguagem é central e decisivo para a ciência do humano, o que explica o termo Interacionismo Sociodiscursivo (Bronckart 1999/2003).

Para o ISD, a consciência e as funções psíquicas superiores do homem (sobretudo o pensamento e a linguagem) são o produto da apropriação e, posteriormente, da interiorização das propriedades das diferentes formações sociais nas quais todos os seres humanos encontram-se inseridos. O ISD postula que as duas maiores unidades de análise são: as ações e os textos. Os últimos podem ser definidos como unidades comunicativas globais, produtos empíricos das ações de linguagem. As ações, que têm estatuto interpretativo, designam uma leitura do agir que implica dimensões motivais e intencionais mobilizadas por uma pessoa particular (Bronckart 2006:213) e materializamse nos textos. Assim, o ISD entende que as relações entre os textos podem ser descritas como relações de mediação, uma vez que o texto é mediador da ação. Na medida em que cada texto se inscreve em um conjunto de textos, ele pertence, segundo o ISD, a um gênero textual (Bronckart 1999/2003:118).

Nosso trabalho baseou-se nas noções de texto e de gênero textual, propostas por Bronckart $(1999 / 2003 ; 2006)$ e nos desdobramentos 
desses conceitos para a Didática das Línguas, sugeridos por Schneuwly e Dolz (1998, 2004). Bronckart (1999/2003), ao retomar a concepção de gênero a partir dos estudos de Volosinov (1929/2010), propõe a terminologia gênero de texto, visto que, para ele, são os textos que se organizam em gêneros, guardando para o termo discurso outro significado. Nesse sentido, os gêneros textuais são construtos históricos, os quais, segundo o mesmo autor (Bronckart 1999/2003:74), se modificam na medida em que as questões sociocomunicativas evoluem. Em outras palavras, os gêneros textuais não são formas fixas e, sim, maleáveis. Além disso, Schneuwly e Dolz (2004:52) observam que a comunicação humana seria praticamente impossível com a inexistência dos gêneros textuais. Os falantes sempre usarão os gêneros textuais, adaptando-os "aos valores particulares da situação em que se encontram" (Machado 2002:25).

Como cada situação de uso da língua se realiza verbalmente através de um gênero, podemos inferir que a capacidade de se comunicar num dado contexto varia de acordo com o domínio que o sujeito tem do gênero a ser usado. Sendo assim, todo indivíduo de uma comunidade linguística, ao agir com a linguagem, é exposto desde seu nascimento a um universo de textos pré-existentes organizados em "gêneros". Essa exposição contínua constrói um conhecimento intuitivo das regras e das propriedades específicas dos diferentes e inúmeros gêneros textuais existentes (Bronckart 1999/2003). Esse conhecimento intuitivo ajuda a produzir textos pertencentes aos gêneros adequados à situação de comunicação em que nos encontramos, principalmente os gêneros com os quais tivemos mais contato (Lousada 2009).

As características dos gêneros, ao serem apropriadas pelo indivíduo, sofrem modificações, como acontece em todos os processos de aprendizagem social (Machado e Cristovão 2006). Assim, todo texto apresenta propriedades genéricas, que resultam da escolha do gênero textual, mas tem especificidades sempre únicas, que resultam das escolhas do produtor em função de sua situação de produção particular (Bronckart 1999/2003). Concluímos, assim, ao lado de Machado (2002:139), que os textos podem apresentar uma notável heterogeneidade, "sobretudo quando pertencentes a gêneros que permitem uma maior liberdade do produtor." 
Diante da diversidade teoricamente ilimitada de gêneros e a variabilidade de sua manifestação concreta (Bronckart 1999/2003), ensinar os alunos a produzirem textos pertencentes aos gêneros textuais acadêmicos, como o artigo científico, é uma tarefa complexa. Para realizá-la, é necessário identificar suas características centrais - ou genéricas para que, somente em seguida, seja possível realizar a "transposição didática dos conhecimentos científicos sobre os gêneros para o nível dos conhecimentos a serem efetivamente ensinados" (Machado e Cristovão 2006: 552). Consideramos, assim, que para ensinar a produzir um gênero textual, é preciso examinar um conjunto de textos que se considera pertencente ao(s) gênero(s) em questão para ser possível analisar suas características centrais. Para tal exame, baseamo-nos no modelo de análise de textos proposto por Bronckart (1999/2003), procurando chegar às suas características comuns.

Segundo esse modelo de análise, iniciamos a caracterização do gênero pelo estudo da situação de ação de linguagem que deu origem ao texto. Diante da necessidade de produzir um texto oral ou escrito, os agentes mobilizam determinadas representações sociais sobre o mundo físico e sociossubjetivo em que estão inseridos (Machado 2002). Um desses conjuntos de representações é o contexto de produção, que pode ser definido como o conjunto dos parâmetros que podem exercer uma influência sobre a forma como um texto é organizado (Bronckart 1999/2003: 93). O contexto de produção físico e sociossubjetivo é constituído pelas representações sobre o local e o momento da produção; pelo emissor e o receptor do texto, considerados do ponto de vista físico, mas sobretudo de seu papel social. Portanto, são consideradas as propriedades sociossubjetivas do contexto de produção, levando-se em conta o lugar social onde se dá a interação e os objetivos ou efeitos que o enunciador-produtor quer atingir com relação ao destinatário (Machado 2002:141). Segundo Machado e Cristovão (2006) a análise do contexto de produção não pode ser enquadrada nos limites de uma análise textual estrutural. Todos os níveis textuais que estamos elencando devem ser vistos em seu valor dialógico, como traços não só do agir do produtor, mas das restrições genéricas relacionadas às atividades e às interações no quadro das quais esse "agir" se realiza. Assim, deve-se analisar o contexto de produção do texto, tanto no nível mais geral do contexto mais amplo, quanto no nível da ação de linguagem que dá origem ao texto. 
Após a análise do contexto de produção físico e sociossubjetivo, examina-se sua organização textual. Bronckart (1999/2003) concebe a organização de um texto como um folhado constituído por três camadas sobrepostas: a infraestrutura geral do texto, os mecanismos de textualização e os mecanismos enunciativos. A primeira camada do folhado textual, a infraestrutura geral do texto, é composta pelo plano global dos conteúdos temáticos, pelos tipos de discurso e pelas sequências. O plano global dos conteúdos temáticos corresponde aos temas que aparecem, podendo ser considerado um resumo do texto. Para Bronckart (1999/2003), os tipos de discursos designam os diferentes segmentos que o texto comporta e correspondem a mundos discursivos construídos na produção textual. Os tipos de discurso podem ser entendidos como pertencentes a dois eixos principais: narrar e expor. $\mathrm{O}$ eixo do narrar (disjunção) envolve a escolha de construir um mundo afastado da ação de linguagem do mundo ordinário. Tal eixo pode ser implicado ou autônomo, ou seja, pode apresentar ou não implicação em relação ao ato de produção (através de dêiticos espaciais, temporais e de pessoa). A implicação e a autonomia referem-se, respectivamente, às instâncias de agentividade presentes ou não nos textos.

Segundo Bronckart (1999/2003), o eixo do expor (conjunção) envolve a escolha de construir um mundo conjunto ao da situação de produção, podendo também ser implicado ou autônomo. Sendo assim, dentro desses dois eixos, há outra divisão que dá origem aos tipos de discurso: narrar - disjunto e autônomo (narração); narrar - disjunto e implicado (relato interativo) e expor - conjunto e implicado (interativo) e expor - conjunto e autônomo (discurso teórico). Lousada (2010) ressalta que a diferença entre gêneros textuais e tipos de discurso é uma das grandes contribuições do ISD. Bronckart (1999/2003: 139) afirma que, enquanto que os gêneros textuais são definidos como uma unidade comunicativa, socio-historicamente elaborada com os recursos de uma dada língua natural e estreitamente dependente das diversas exigências interativas das situações de atividade geral, os tipos de discurso são unidades linguísticas em número restrito, suscetíveis de entrar na composição de qualquer gênero, chamadas de «mundos discursivos ».

Bronckart (1999/2003), baseando-se em Adam, retoma a noção de sequência, que designa modos de planificação da linguagem que se desenvolvem localmente, no interior do plano geral do texto. Elas 
podem estar ou não presentes no texto - diferindo assim dos tipos de discurso - e aparecem na maioria das vezes combinadas, sendo pouco provável encontrar em um texto somente um tipo de sequência. A organização linear do texto pode ser concebida como o produto da combinação e da articulação de diferentes tipos de sequência (Bronckart 1999/2003: 218). Elas se classificam em: narrativa, descritiva, argumentativa, explicativa, injuntiva e dialogal. Para Bronckart (1999/2003), o grau zero da sequência narrativa, na qual não há intriga ou tensão, chama-se script. Por outro lado, o grau zero das sequências argumentativa e explicativa, a esquematização, é mobilizado quando não há a necessidade de explicar algo de difícil compreensão ou argumentar em favor ou contra algo que pode ser contestável. É da diversidade das modalidades de articulação e combinação das sequências que decorre a heterogeneidade na composição da maioria dos textos (Bronckart 1999/2003: 219). Outro aspecto importante a salientar no que diz respeito às sequências é seu estatuto dialógico, pois a escolha de uma delas pelo produtor do texto depende do contexto de produção e da imagem que ele tem de seu destinatário.

Segundo o mesmo autor, os mecanismos de textualização constituem o segundo nível do folhado textual, que exploram os recursos linguísticos para assegurar a progressão temática e são caracterizados pela conexão e pela coesão. A conexão diz respeito às relações entre os níveis de organização do texto e é explicitada pelos organizadores textuais, revelando a relação entre as macroideias do texto. A coesão pode ser dividida em coesão nominal (retomadas nominais e pronominais; anáforas e catáforas) e verbal (tempos e modos verbais).

No terceiro nível do folhado textual, encontramos os mecanismos enunciativos que dão a clarificação dialógica do texto, compostos pelas vozes presentes no texto e as modalizações. As modalizações são responsáveis pelas diversas avaliações do enunciador sobre um ou outro aspecto do conteúdo temático e podem ser divididas, segundo Bronckart (1999/2003) em lógicas, deônticas, pragmáticas e apreciativas. As modalizações lógicas são avaliações apoiadas em critérios elaborados e organizados no quadro das coordenadas formais que definem o mundo objetivo; as deônticas baseiam-se em critérios elaborados e organizados no quadro das coordenadas formais que definem o mundo social; as apreciativas fundamentam-se em critérios elaborados e organizados 
no quadro das coordenadas formais que definem o mundo subjetivo e as pragmáticas contribuem para a explicação de alguns aspectos da responsabilidade de uma entidade constitutiva do conteúdo temático. As vozes explicitam as instâncias que assumem ou se responsabilizam pelo que está sendo dito. É importante ressaltar que diferentes vozes podem se expressar em um texto, podendo ser reagrupadas em três subconjuntos (Bronckart 1999/2003: 131): a voz do autor empírico, as vozes sociais, as vozes de personagens. Elas podem estar implícitas no texto, não sendo traduzidas por marcas linguísticas específicas.

Para analisar os mecanismos enunciativos presentes o texto, Bronckart (1999/2003) sugere o recurso a outras teorias que complementem o que é apresentado nos estudos do ISD. Lousada (2010) sugere autores tais como Maingueneau (1991, 2001), Authier-Revuz (2001), entre outros para esse aprofundamento.

No que diz respeito ao uso do conceito de gêneros no âmbito educacional, é importante lembrar que vários pesquisadores do ISD examinaram as relações entre os gêneros textuais e os processos de ensino e aprendizagem, dentre eles, Dolz, Pasquier e Bronckart (1993), Schneuwly e Dolz (2004), Dolz, Gagnon e Toulou (2008) e Machado (2000). Alguns desses autores partiram dos pressupostos vigotskianos sobre o desenvolvimento na ontogênese e propuseram algumas noções que têm por objetivo pensar na questão do ensino dos gêneros textuais: capacidades de linguagem, modelo didático e sequência didática.

O termo "capacidades de linguagem" faz referência às "aptidões requeridas do aprendiz para a produção de um gênero numa situação de interação determinada" (Schneuwly e Dolz 2004:52). Segundo Dolz, Pasquier e Bronckart (1993), elas são classificadas em: capacidades de ação, capacidades discursivas e capacidades linguístico-discursivas, podendo ser consideradas como fundamentos para o domínio de uma língua. As capacidades de linguagem encontram-se em interação constante, durante todo o processo de produção de textos, embora, para efeito de classificação, estejam assim divididas (Machado 2001:140).

As capacidades de ação mobilizam as representações sobre as características do contexto de produção do texto e os conhecimentos de mundo envolvidos na produção textual. As capacidades discursivas, por sua vez, implicam o gerenciamento da infraestrutura geral do 
texto (Machado 2001:140) como a escolha dos tipos de discurso e das sequências textuais e, ainda, a elaboração e organização dos conteúdos temáticos dizíveis através dos textos. Finalmente, as capacidades linguístico-discursivas mobilizam os mecanismos de textualização e enunciativos, sendo elas responsáveis pelo gerenciamento das vozes, modalizações e pelos mecanismos de coesão verbal, nominal e conexão (Lousada 2002). Conforme dito acima, as capacidades de linguagem estão em interação contínua, pressupondo-se que: i) o desenvolvimento de uma delas pode levar ao desenvolvimento das outras (Machado 2001:144); ii) elas podem ser mobilizadas na produção de outros gêneros textuais, para outras situações de comunicação (Lousada e Abreu-Tardelli 2010:50).

Segundo De Pietro et al. (1996/1997), o modelo didático é um objeto descritivo e operacional, sendo construído para apreender o fenômeno complexo da aprendizagem de um gênero e orientar as práticas escolares. O modelo didático apontará "os aspectos centrais a serem trabalhados, com base em uma análise a priori, isto é, sem se levar em conta o nível dos alunos nem as particularidades de uma classe" (Schneuwly e Dolz 1998:100). Ele evidencia as dimensões ensináveis, a partir das quais as sequências didáticas podem ser concebidas (Schneuwly e Dolz 2004:63), não sendo um objeto teoricamente puro, mas, ao contrário, um modelo pensado em função do uso do gênero textual para fins didáticos. Para a construção de um modelo didático do gênero, deve-se levar em conta: os estudos sobre o gênero em si; as pesquisas sobre desenvolvimento e sobre as características dos textos; o conhecimento sobre as práticas sociais ligadas ao gênero; as capacidades e as dificuldades dos alunos em trabalhar com textos do gênero selecionado, entre outros (Schneuwly e Dolz 1998). Ao lado desses princípios fundadores, é necessário examinar o corpus de textos coletado segundo o modelo de análise de textos proposto por Bronckart (1999/2003), sobretudo quando se trata de uma língua estrangeira, já que, nesse caso, o contato menos frequente de professores e alunos com textos autênticos produzidos na língua ensinada pode levar a uma concepção equivocada sobre as características frequentes dos textos pertencendo ao gênero em questão.

A partir do modelo didático produzido e das características centrais do gênero é possível montar uma sequência didática, ou seja, um 
"conjunto de atividades organizadas de maneira sistemática, em torno de um gênero textual oral ou escrito" (Schneuwly e Dolz 2004:97). Essas atividades são integradas por um objetivo unificador, "as diferentes dimensões constitutivas de um gênero em específico, que são consideradas estimáveis para um determinado nível de ensino" (Machado 2001:138). O papel da sequência didática consiste em propor um conjunto de atividades que "propicie a transposição didática adequada de conhecimentos sobre o gênero, ao mesmo tempo em que explora a esfera de circulação de textos produzidos" (Cristovão 2010:307). Tais atividades devem possibilitar o desenvolvimento das capacidades de linguagem necessárias para a produção de textos pertencentes aos gêneros textuais que circulam na sociedade, devendo englobar práticas de escrita, de leitura e práticas orais e realizar uma verdadeira "sistematização para que o aluno possa realmente apropriar-se de uma determinada prática de linguagem" (Barros 2009:134).

A sequência didática destina-se a ajudar os alunos a melhor dominar um gênero textual, permitindo-lhes escrever ou falar de uma maneira mais apropriada em uma determinada situação de comunicação, através de uma sequência composta de: (1) apresentação da situação e do gênero, (2) produção inicial para avaliar as capacidades já adquiridas e as que devem ainda ser desenvolvidas para o melhor domínio do gênero, (3) módulos constituídos de diversas atividades e exercícios a fim de fornecer os meios necessários para esse domínio e (4) produção final para colocar em prática os conhecimentos adquiridos e mensurar o progresso (Schneuwly e Dolz 2004).

A SD se inicia, portanto, com a apresentação da situação ou do problema de comunicação que será resolvido pela produção final do texto pertencente ao gênero em questão pelos alunos. Esse é o momento "em que a turma constrói uma representação da situação de comunicação e da atividade de linguagem a ser executada" (Schneuwly e Dolz 2004:99), fornecendo aos aprendizes os esclarecimentos e instruções necessários para que conheçam "o projeto comunicativo visado e a aprendizagem de linguagem a que está relacionado" (Schneuwly e Dolz 2004:100). Essa fase da SD possui crucial importância, uma vez que o trabalho com o gênero passa a ser fruto de uma necessidade de interação, "já que a linguagem sempre está consubstanciada em uma prática social” (Barros 2009:134). 
A segunda etapa da SD é a primeira produção (ou produção inicial). Nela, os alunos produzem seu primeiro texto, revelando "para si mesmos e para os professores as representações que têm dessa atividade" (Schneuwly e Dolz 2004:101). Essa produção inicial serve como ponto de partida para o professor elaborar as atividades subsequentes, possibilitando-lhe identificar o que o aluno já sabe sobre o gênero e detectar suas maiores dificuldades (Petreche 2009:246), definindo os pontos em que são necessárias intervenções - o que é preciso trabalhar mais para desenvolver as capacidades de linguagem dos aprendizes - e o caminho que o aluno tem ainda a percorrer. Em outras palavras, a produção inicial tem como objetivo identificar o desenvolvimento real dos alunos, no sentido vigotskiano, identificando quais capacidades linguageiras eles ainda precisam desenvolver. Dessa forma, "a produção inicial pode 'motivar' tanto a sequência como o aluno" (Schneuwly e Dolz 2004:101).

A terceira fase que compõe a sequência didática são os módulos, também chamados de ateliers, ou oficinas. Os módulos são oficinas que permitem melhorar a leitura e escrita dos alunos (Dolz 2009:168), possibilitando que eles realizem diferentes atividades "direcionadas para o projeto de apropriação das características fundamentais do gênero estudado" (Machado 2000:15). Nas oficinas, os alunos exploram o gênero, de forma que possam analisá-lo sob vários ângulos. Nesse estágio da $\mathrm{SD}$, são trabalhados os problemas que apareceram na primeira produção, abordados um a um e separadamente.

A quarta e última etapa da SD é a produção final, em que o aprendiz coloca em prática as noções e conhecimentos adquiridos. Essa produção também permite ao professor realizar uma avaliação (Schneuwly e Dolz 2004:106), efetuando a avaliação do desenvolvimento real do aluno por meio da comparação com a primeira produção. Na produção final, efetuam-se "observações, análises e a avaliação dos progressos conseguidos e das dificuldades ainda não superadas" (Machado e Cristovão 2006:556).

É necessário também que o próprio aluno avalie seus avanços e progressos no processo de desenvolvimento de suas capacidades de linguagem. Para isso, durante o processo da SD, é importante que se construa uma ficha de controle do aluno, que "resumindo objetivos e 
atividades específicas de cada atelier, deveria lhes servir como orientação para a revisão da produção inicial e como ficha de avaliação para o professor" (Machado 2000: 18). Esse roteiro de avaliação é relevante, pois permite aos alunos compreenderem os comentários avaliativos do professor, uma vez que é utilizado "um vocabulário conhecido pelas duas partes" (Schneuwly e Dolz 2004:107). Dessa forma, além da avaliação, a grade possibilita a observação da aprendizagem efetuada por parte do aluno e permite ao professor planejar a continuação do trabalho, retornando eventualmente a pontos mal-compreendidos ou mal-apropriados. Segundo Machado (2000:23),

mais do que levar o estudante à maestria de um determinado gênero, a SD pode conduzi-lo à percepção e à apropriação de certos procedimentos (ou de certas operações de linguagem), indispensáveis à produção de qualquer gênero, o que pode contribuir para desenvolver sua capacidade de sozinho, apreender as dimensões constitutivas de um texto que devem ser observadas e analisadas quando se defrontar diante do desafio de produzir um texto pertencente a um gênero que não lhe foi formalmente ensinado.

Além disso, é importante lembrar que o desenvolvimento das capacidades de linguagem promovido pela SD não ocorre linearmente, sendo visto como um processo espiralado, como aponta Beato-Canato (2008: 44):

as características presentes no texto inicial do aprendiz podem ou não estar presentes nas versões subsequentes, e inadequações podem ser encontradas na versão final, até mesmo de aspectos aparentemente conhecidos pelos aprendizes em versões anteriores. Isso se dá pelo fato do aprendiz estar em processo de desenvolvimento das capacidades de linguagem.

No caso do ensino e aprendizagem de línguas estrangeiras, Guimarães-Santos (2012) nos chama a atenção para outros aspectos que devemos ter em mente ao preparar uma SD levando em conta esse contexto específico: manter a diversidade das capacidades de linguagem trabalhadas na SD, não negligenciar a modalidade oral, prever alternância entre atividades escritas e orais e, sempre que possível, é recomendável que as sequências didáticas se insiram em um projeto de classe, tornando as atividades de aprendizagem mais significativas e pertinentes. 
Em suma, na perspectiva dos estudos sobre didática das línguas que apresentamos, acredita-se que é por meio de uma sequência didática, construída a partir de um modelo didático e com o objetivo de ensinar um gênero textual que as capacidades linguageiras dos alunos poderão se desenvolver. Para explicar essa hipótese, lembremos alguns pressupostos da perspectiva vygotskiana, que estão na base do ISD. Para Vigotski (1997), a relação do homem com o mundo se dá por meio de ferramentas operadas pelo homem no processo de trabalho ou, ainda, por meio de instrumentos que realizam a mediação entre ele, o mundo e seus objetos; entre ele e os outros; e entre ele e si-mesmo. Friedrich (2012), em seu estudo sobre o conceito vigotskiano de mediação, considera que o homem desenvolveu, ao longo de sua história, tanto instrumentos materiais, que operam transformações nos objetos do mundo (como uma pá, por exemplo), quanto instrumentos simbólicos, ou psicológicos, dentre os quais a linguagem, o cálculo matemático, entre outros. A partir dessa noção, consideramos os gêneros textuais instrumentos, que estão à disposição dos sujeitos em uma sociedade, em um determinado momento. Os indivíduos podem utilizá-los para agir com a linguagem, porém isso só ocorrerá se tiver havido um processo de apropriação desses gêneros, transformando-os em instrumentos psicológicos que atuam nas capacidades linguageiras internas. Sendo assim, nossa perspectiva difere das abordagens que consideram que a linguagem é uma ferramenta externa ao sujeito e da qual ele se serve em ocasiões determinadas. Dessa forma, podemos dizer que adotamos a noção de gênero textual não apenas como unidade de ensino, mas como um instrumento que atua no processo de aprendizagem (Schneuwly e Dolz 2004). É precisamente nesse sentido que afirmamos que o ensino de gêneros textuais pode possibilitar o desenvolvimento das capacidades de linguagem dos alunos.

\section{Gêneros textuais acadêmicos: uma experiência na disciplina monografia}

Como dissemos, nossa proposta foi de relatar uma experiência piloto de trabalho com o gênero textual artigo científico em uma disciplina de literatura, na graduação em Letras, Habilitação em Francês da FFLCH-USP. A experiência faz parte do projeto do Laboratório de 
Letramento Acadêmico ${ }^{3}$, criado no segundo semestre de 2011, na FFL$\mathrm{CH} / \mathrm{USP}$, que tem como foco o desenvolvimento da escrita acadêmica. O Laboratório, atualmente, oferece atendimento à comunidade interna da USP, procurando solucionar questões quanto à produção de textos acadêmicos em francês, em português e em inglês. Os atendimentos são personalizados, tendo por objetivo apresentar estratégias para que os alunos possam escrever melhor, adequando seus textos ao que é esperado dos gêneros acadêmicos. Vejamos, então, como se desenvolveu a experiência piloto.

Durante o segundo semestre de 2013, foi desenvolvido um trabalho junto aos alunos que cursavam Monografia ${ }^{4}$, disciplina obrigatória do bacharelado em Francês na FFLCH. Essa disciplina teve como trabalho final a escrita de um artigo científico que tratasse de algum aspecto da obra de Pascal Quignard. Escolhemos essa disciplina por ser a última disciplina obrigatória da Habilitação em língua francesa, momento em que os alunos já possuem (ou espera-se que possuam) conhecimentos específicos tanto sobre a língua quanto sobre a literatura francófona, permitindo que os professores esperem que eles sejam capazes de propor reflexões sobre a(s) obras(s) do autor em questão na forma de um artigo científico. Nesse momento do curso, os alunos estão quase terminando o bacharelado em Letras e, portanto, podemos inferir que estão perto de serem considerados "especialistas". No entanto, seu nível linguístico é bem variável, assim como sua formação enquanto "pesquisadores", já que alguns podem ter desenvolvido trabalhos de Iniciação Científica, outros não. Foram oferecidos aos alunos dois tipos de ajuda: i) plantões para os alunos, em horários fora das aulas; ii) participação na aplicação de uma sequência didática, em sala de aula e com o acompanhamento da professora responsável pela disciplina.

3. O Laboratório de Letramento Acadêmico foi criado em 2011 por professores do DLMFFLCH-USP. A proposta inicial foi da Profa. Dra. Marília Ferreira, para a área de inglês, e tem sido desenvolvido desde o início também na área de francês, sob coordenação da Profa. Dra. Eliane G. Lousada.

4. A disciplina foi ministrada, no $2^{\circ}$ semestre de 2013, pela Profa. Dra. Verónica Galindez Jorge, a quem agradecemos pela disponibilidade em realizar a experiência piloto. Os alunos da disciplina estão cursando o $10^{\circ}$ semestre da Habilitação em Francês, têm nível B2 do Quadro Comum Europeu de Referência para as Línguas (Conseil de l'Europe, 2001) e devem desenvolver um artigo científico sobre um autor/obra literária estudado(a) no curso. 
No decorrer do semestre, a professora responsável pela disciplina Monografia, pediu aos alunos que propusessem primeiramente um projeto de pesquisa que teria como resultado o artigo. Ela leu os projetos e sugeriu direcionamentos que buscavam ajudar os alunos no desenvolvimento da proposta, indicando bibliografia ou fazendo perguntas que os levassem a repensar o que propuseram; em seguida, os alunos produziram uma primeira versão dos artigos, que também foi lida e comentada. Além disso, na aulas da disciplina, as obras do autor em questões foram discutidas e a professora responsável pela disciplina disponibilizou horários de atendimento individualizado para os alunos, permitindo que eles pudessem discutir com ela o trabalho a ser desenvolvido. Ao final do semestre, os alunos deveriam entregar a versão final de seus artigos.

Cientes desse contexto e baseando-nos em nossa perspectiva teórico-metodológica, iniciamos a experiência piloto pela elaboração do modelo didático do artigo científico. Para realizar a seleção do corpus, utilizamos o trabalho já desenvolvido por Barioni (2012), já que, em sua pesquisa sobre resumos e resenhas, a pesquisadora fez um levantamento junto aos professores da área de Área de Estudos Linguísticos, Literários e Tradutológicos em Francês da FFLCH/USP para saber quais eram as revistas científicas que eles consultavam com mais frequência, chegando às seguintes publicações ${ }^{5}$ Lexicometria, Voix Plurielles, Acelf(revista Éducation et Francophonie), Lidil, Mélanges Crapel, Les Langues Modernes, Ripes e Synergies.

Para a coleta de nosso corpus, realizamos três mudanças no que se refere às revistas usadas por Barioni (2012): retiramos do corpus a revista Les Langues Modernes, pois ela não disponibiliza gratuitamente os artigos, apenas os resumos dos mesmos; optamos por selecionar um artigo da revista Synergies Europe, enquanto Barioni trabalhou com revistas Synergies de outras partes do mundo; e, por fim, realizamos uma troca, adotamos a revista Recto-Verso no lugar de Lexicometria, por dois motivos: Recto-Verso nos foi indicada pela professora ministrante da disciplina e, também, porque a publicação traz artigos de 
jovens pesquisadores, o que a aproxima do público potencial de nossa sequência didática.

Após o levantamento das publicações, estabelecemos alguns critérios para a determinação do corpus no qual nos baseamos para elaborar o Modelo Didático do artigo científico:

- coleta de um artigo de cada revista, chegando ao total de 7 artigos que analisamos;

- seleção de um artigo do número mais recente disponível para consulta na internet de cada publicação;

- escolha dos artigos buscando contemplar pesquisadores de diversas universidades em várias partes do mundo, levando em consideração os cargos ocupados por eles, procurando os mais prestigiados;

- seleção de artigos das áreas de ensino e estudos literários;

- inclusão de um artigo de um doutorando, por imaginarmos que os alunos da graduação podem se identificar com esse pesquisador.

Após a seleção do corpus, realizamos as análises seguindo o modelo proposto por Bronckart (1999/2003, 2006) que observa primeiramente o contexto de produção, físico e sociossubjetivo. Depois, analisamos os textos de acordo com a arquitetura textual (Bronckart 1999/2003) em que são observadas as três camadas superpostas que constituem o texto: infraestrutura geral do texto (plano global dos conteúdos temáticos, tipos de discurso e sequências), mecanismos de textualização (conexão e coesão nominal) e mecanismos enunciativos (posicionamento enunciativo, modalizações e vozes do texto). A partir das análises e da literatura disponível sobre o assunto, construímos o modelo didático do gênero artigo científico, ou seja, identificamos as características presentes em todos os textos pertencentes ao corpus, com a finalidade de identificar as características genéricas. A seguir, apresentamos o modelo didático do artigo científico em francês. 
O contexto de produção do artigo científico é representado por um enunciador que é um pesquisador que tem por objetivo divulgar resultados (parciais ou finais) de sua pesquisa. Ele escreve, em primeira instância, para um avaliador, afinal o artigo precisa ser aceito pelos pareceristas e pela comissão científica da revista. Em um segundo momento, o texto tem como destinatário um público específico, com alguns conhecimentos prévios sobre o tema. Em relação ao local social de circulação dos artigos, pode-se dizer que algumas revistas científicas são geralmente ligadas a Universidades ou a Grupos de Pesquisa. O objetivo mais imediato do artigo é ser publicado pela revista, chegando em seguida ao objetivo principal: divulgar a pesquisa realizada. Os objetivos secundários são: apresentar os resultados obtidos, discutir o que se está pesquisando com os pares ao colocar um tema em discussão e ser considerado um pesquisador que desenvolve uma pesquisa digna de publicação, já que ter artigos publicados em revistas indica que a pesquisa é respeitável. Em relação ao momento da publicação, o texto é escrito alguns meses antes da publicação, pois deve ser submetido ao comitê científico dentro das datas previstas, sempre algum tempo antes (meses ou semanas). O artigo poderá ser lido logo após a publicação da revista e fica disponível para consulta por tempo indeterminado, seja no formato virtual (as revistas costumam ter arquivos disponíveis online), seja no formato impresso (por exemplo em bibliotecas universitárias).

Em relação à infraestrutura geral do texto, os artigos costumam ter a seguinte apresentação: título, nome do autor, resumo, texto separado por entretítulos, referências bibliográficas e notas. Alguns artigos não trazem o resumo no corpo do texto, ele fica apenas no "índice" da revista. Os textos têm três grandes partes: introdução, desenvolvimento e conclusão e/ou considerações finais ${ }^{6}$. A introdução compreende: apresentação do tema, detalhamento de um aspecto, apresentação de uma lacuna que justifique a realização do estudo, especificação dos objetivos do artigo, podendo ser seguida do plano de estruturação do artigo. Já o desenvolvimento costuma conter: apresentação do contexto de pesquisa, detalhamento do quadro teórico e da metodologia de pes-

6. O desenvolvimento em três partes canônicas não acrescenta muito ao que já se sabe sobre textos científicos. Porém, parece-nos importante ressaltar que essa divisão resulta da necessidade de levar em conta os artigos da área de literatura, que diferem bastante dos das áreas de Didática e Tradução. 
quisa usados, apresentação dos dados e sua análise. Por fim, a conclusão traz uma síntese dos resultados e, normalmente, ressalta a importância de alguns dos aspectos encontrados na pesquisa apresentada, podendo também sugerir novas pesquisas ou novos direcionamentos para a área em questão. $\mathrm{O}$ uso de entretítulos nos textos é recorrente, eles podem ser descritivos, como "metodologia", ou podem funcionar como uma "pista" de leitura, apresentando a principal temática explorada no bloco de texto que segue. Quanto aos tipos de discurso, encontramos um misto de discurso interativo e teórico, com predominância do discurso teórico. O discurso interativo aparece apenas em casos em que o contexto de desenvolvimento da pesquisa é mencionado, ou alguma outra etapa que envolva o pesquisador e autor do artigo. No que diz respeito às sequências, é importante dizer que, no artigo científico, predomina uma sequência argumentativa global, que se desenvolve ao longo do artigo inteiro, pois é necessário estabelecer um efeito argumentativo global em relação à problemática abordada no artigo. Paralelamente, foram encontradas sequências explicativas e descritivas. As sequências descritivas aparecem em menor número, apenas quando se trata de descrever procedimentos, métodos etc. As sequências explicativas são empregadas quando o produtor do texto julga necessário explicar algum termo considerado de difícil entendimento pelo destinatário.

No que diz respeito aos mecanismos de textualização, observamos que a conexão se dá por meio de conectores argumentativos e sequenciais. Além disso, identificamos o uso de entretítulos e pontuação, para assegurar a conexão entre as partes e entre as ideias. Da mesma forma, alguns conectores argumentativos se repetem como: d'une part/d'autre part, et, car, puisque, ainsi, toutefois. A coesão nominal se dá por retomadas das palavras-chave do artigo, repetidas várias vezes, e pelo uso de pronomes. Ainda no âmbito da coesão nominal, é importante mencionar as fórmulas fixas usadas para introduzir os objetivos : « cet article a comme but de faire l'inventaire ", "Dans cet article, nous nous proposons d'effectuer ", " cet article développe la réflexion sur », "la présente recherche se propose d'analyser », "nous étudierons donc la place occupée par ", "dans cet article, nous avons comme objectif», entre outras. Os verbos encontrados estão geralmente no tempo presente, com exceção de alguns verbos no passado, quando é necessário contar a pesquisa desenvolvida ou no futuro, para enumerar os próximos passos. Os verbos recorrentes são: amener, mener, présenter, analyser, 
développer, montrer, proposer, dire, voir, commencer, trouver, discuter, penser, analyser, expliquer, s'avérer, entre outros.

Quanto aos mecanismos enunciativos, observamos que o posicionamento enunciativo do pesquisador nos textos pode variar, sendo que na maior parte do corpus existe o uso predominante do "nous" para falar da pesquisa. $\mathrm{O}$ "eu" pode ser usado em algumas situação, como em artigos que são advindos de conferências transcritas. $\mathrm{O}$ "on" está presente nos artigos com diversos valores. Estão presentes nos textos outras vozes, entre elas a voz dos teóricos citados, trechos da obra literária ou filosófica a ser analisada e também, em alguns casos, os dados que são objeto da análise do artigo. A voz dos teóricos é usada para dar credibilidade à pesquisa e para evitar que o autor assuma a responsabilidade sobre os aspectos teóricos. Os aportes teóricos podem ser mencionados ou explicados e são inseridos no texto por meio de paráfrase ou de citações das obras. No caso dos trechos de obras ou dos dados, percebemos que há sempre um comentário analítico ou explicativo que precede ou sucede o excerto. Há grande quantidade de modalizações lógicas nas análises ou nos resultados. As modalizações apreciativas também são frequentes, podendo caracterizar os dados ou exprimir pontos de vista. Já as modalizações deônticas são pouco usadas.

As características que apresentamos, identificadas a partir de estudos já desenvolvidos sobre o gênero artigo científico e de nossas análises, serviram de base para a elaboração da sequência didática e para a análise dos textos produzidos pelos alunos.

\section{A sequência didática}

A partir do modelo didático acima apresentado e também das dificuldades observadas nas primeiras versões dos artigos entregues pelos alunos, propusemos uma sequência didática que tinha como principais objetivos:

- discutir a situação de produção do artigo científico: para quem os alunos escrevem e com qual objetivo; 
- trabalhar a organização textual da introdução do artigo científico;

- explorar as diferentes maneiras de posicionar-se enunciativamente;

- propor estratégias de revisão para que os alunos pudessem revisar seus próprios textos.

A sequência didática foi ministrada em duas aulas (cada aula tem duração de 90 minutos) logo após a entrega da primeira versão do artigo. Na primeira, o foco estava na situação de produção, já na segunda, exploramos aspectos textuais e apresentamos a ficha de auto-avaliação.

Optamos por nos focar na situação de produção, pois, nas primeiras versões, os alunos pareciam escrever para si mesmos, ignorando o leitor. Os textos tinham lacunas que dificultavam a compreensão dos objetivos dos artigos ${ }^{7}$. Para tratar desse tema, propusemos discussões em pequenos grupos sobre a situação de ação de linguagem que dá origem aos artigos científicos:

Excerto 1 - Sequência didática ${ }^{8}$

Discutez à trois :

a. Tous les textes ont un destinataire potentiel. Quand vous écrivez des textes à l'université, à qui écrivez-vous ?

b. Au moment où vous écrivez vos travaux à l'université, pensez-vous à votre lecteur? Si oui, quelles sont vos préoccupations ? Pensez-vous à plaire à ce lecteur potentiel ? De quelle(s) manière(s) ?

c. Quand un professeur vous demande un travail, comme un essai ou un compte rendu, que pensez-vous qu'il veut évaluer? Quel est l'objectif à accomplir?

7. Antes de entregar a primeira versão do artigo, os alunos haviam feito um projeto de pesquisa detalhando os objetivos de seus futuros artigos. A professora responsável pela disciplina não os considera para a avaliação, mas comenta os projetos, dando sugestões para o desenvolvimento do artigo.

8. Trata-se de uma sequência didática produzida pelas autoras (TONELLI, Jaci Brasil; LOUSADA, Eliane Gouvêa, 2014) para o ensino do artigo científico para a área de estudos literários, que não foi publicada. 
Na proposta de discussão, as metas principais eram questionarse sobre o leitor dos trabalhos universitários e sua relação com eles. Propusemos ainda outras discussões sobre os objetivos desse gênero textual e estudamos detalhadamente dois resumos.

Na segunda aula, passamos à leitura de um artigo para que os alunos observassem como a introdução é construída. Para isso, elaboramos as seguintes atividades:

Excerto 2 - Sequência didática

1. Lisez le premier paragraphe de l'article « Genèse et postérité du bio-pouvoir » et identifiez les types d'informations données au lecteur.

2. Dans quel ordre les informations classées sont-elles données?

3. En tant que lecteur, quelle a été la fonction de ces deux paragraphes ? Quelle est leur importance pour l'article?

4. Par quel moyen l'auteur explique-t-il au lecteur la thématique de l'article?

Exploramos também as diferentes maneiras que o autor do artigo usou para expor suas reflexões, por meio da questão abaixo:

Excerto 3 - Sequência didática

2. Comment l'auteur exprime-t-il ses réflexions? Quelles sont les « formules » qu'il utilise pour le faire?

Ressaltamos que, no artigo usado na sequência didática, há diversas maneiras de se posicionar enunciativamente: o autor usa, inclusive, a primeira pessoa do singular. Efetuamos essa escolha em conjunto com a professora responsável pela disciplina, que não vê problema no uso do "eu" nos artigos que lhe serão entregues, chegando mesmo a incentivar os alunos a optarem por esse posicionamento.

Nessa aula, buscamos também mostrar aos alunos que os pesquisadores, ao escrever, desejam que o leitor compreenda com facilidade 
os pontos cruciais do estudo apresentado. Para tal, fizemos com que procurassem as estratégias usadas pelo pesquisador para explicar os conceitos ou pontos mais difíceis citados no artigo.

Por fim, propusemos alguns quadros para que os alunos pudessem revisar seus artigos. O primeiro retomava a situação de produção, mas mostrava alguns elementos já dados, para facilitar a reação dos alunos:

Excerto 4 - Sequência didática

Pour mieux élaborer votre article scientifique, nous vous proposons quelques
astuces.
1. Complétez ce tableau avec les caractéristiques potentielles de votre texte:
\begin{tabular}{|l|l|}
\hline Auteur & \\
\hline Fonction sociale de l'auteur & $\begin{array}{l}\text { Professeur qui connait les œuvres de } \\
\text { Quignard. }\end{array}$ \\
\hline Destinateur réel & $\begin{array}{l}\text { Quelqu'un qui ne connaît pas bien } \\
\text { l'œuvre de Pascal Quignard, mais qui } \\
\text { s'y intéresse. Même si le destinataire } \\
\text { réel est le professeur, l'auteur/étudiant } \\
\text { doit écrire ayant dans l'esprit quelqu'un } \\
\text { qui n'est pas un spécialiste, comme la } \\
\text { monitrice du Laboratoire de Littératie } \\
\text { Académique ou n'importe quel autre } \\
\text { lecteur. }\end{array}$ \\
\hline $\begin{array}{l}\text { Image que l'auteur doit avoir de son } \\
\text { destinataire possible }\end{array}$ \\
\hline $\begin{array}{l}\text { Lieux et médias où le texte pourrait } \\
\text { circuler. }\end{array}$ & \\
\hline Moment de production & \\
\hline Objectif de l'auteur & \\
\hline
\end{tabular}

O segundo era uma ficha de auto-avaliação do artigo, visando a verificar se o artigo escrito pelo aluno adequava-se ao gênero textual: 
Excerto 5 - Sequência didática

4. Après avoir fini votre article, comme dans une recette, laissez-le reposer au moins $24 \mathrm{~h}$. Ensuite, relisez votre texte pour l'évaluer à partir de la fiche ci-dessous.

\section{Fiche d'auto-évaluation:}

\begin{tabular}{|l|l|l|l|}
\hline & Oui & $\begin{array}{l}\text { Plus ou } \\
\text { moins }\end{array}$ & Non \\
\hline $\begin{array}{l}\text { Le texte vous semble approprié aux objectifs d'un } \\
\text { article scientifique. }\end{array}$ & & & \\
\hline $\begin{array}{l}\text { Le texte vous semble approprié à vos destinataires } \\
\text { (c'est-à-dire une personne qui s'intéresse aux œuvres de } \\
\text { Pascal Quignard, mais n'est pas un spécialiste). }\end{array}$ & & & \\
\hline $\begin{array}{l}\text { Le texte transmet l'image que vous souhaitez de vous- } \\
\text { même. C'est-à-dire d'un étudiant qui a lu l'œuvre } \\
\text { de Pascal Quignard et qui a trouvé un aspect pour } \\
\text { développer une analyse. }\end{array}$ & & & \\
\hline $\begin{array}{l}\text { Les objectifs de votre article sont exprimés de manière } \\
\text { claire. }\end{array}$ & & & \\
\hline $\begin{array}{l}\text { Vous avez discuté d'une question liée à une œuvre de } \\
\text { Quignard en utilisant des extraits de ses livres. }\end{array}$ & & & \\
\hline $\begin{array}{l}\text { Vous avez utilisé un appui théorique pour sous-tendre } \\
\text { vos réflexions. }\end{array}$ & & & \\
\hline $\begin{array}{l}\text { Vous arrivez à exprimer de manière assez claire vos } \\
\text { réflexions sur l'œuvre ou la thématique traitée dans } \\
\text { votre article. }\end{array}$ & & & \\
\hline Vos titres et sous-titre guident le lecteur. & & & \\
\hline $\begin{array}{l}\text { À la fin de votre article, vous avez atteint les objectifs } \\
\text { proposés au début. }\end{array}$ & & & \\
\hline Vous avez bien relié vos idées à l'aide des connecteurs. & & & \\
\hline $\begin{array}{l}\text { Vous avez utilisé les verbes appropriés pour traduire } \\
\text { votre pensée. }\end{array}$ & & & \\
\hline $\begin{array}{l}\text { Il n'y a pas de problèmes de ponctuation, phrases } \\
\text { incomplètes, erreurs grammaticales ou d'orthographe. }\end{array}$ & & & \\
\hline
\end{tabular}

O último quadro trazia uma síntese dos principais erros linguísticos encontrados nas primeiras versões e sugestões para corrigi-los: 


\section{Excerto 6 - Sequência didática}

5. Après avoir vérifié si votre texte possède toutes les caractéristiques d'un article scientifique, passons à la révision « linguistique ». Utilisez la fiche suivante comme base pour éviter les erreurs les plus fréquentes:

\section{Fiche de révision :}

\section{Problèmes}

Les phrases sont trop longues et il est difficile d'en comprendre le sens.

Mauvais usage de que/qui.

Accord sujet - verbe

Féminin et masculin

Pour/Par

Pronoms compléments : le, la, les ; lui, leur

Adéquation du vocabulaire

\section{Conseils}

Faites des phrases plus courtes (moins de subordination) pour faciliter la compréhension de ce que vous voulez dire.

Relisez la phrase pour découvrir si le « que-i » est l'objet direct (que) ou le sujet (qui) de la deuxième phrase.

Quand on écrit des phrases un peu longues on oublie si le sujet était au singulier ou au pluriel ; relisez donc les phrases pour éviter ce problème. N'oubliez pas que dans la majorité des cas la sonorité est la même, mais la forme écrite est différente.

Vérifiez toujours dans un dictionnaire si le mot que vous utilisez est féminin ou masculin, pour ensuite accorder le déterminant (le/la, un/une, ce/cet/cette), les qualificateurs et, des fois, les participes passés.

Regardez ces exemples pour comprendre l'usage de « par» et « pour»:

Ce livre a été écrit par Quignard.

J'ai acheté ce livre pour toi.

Vérifiez attentivement si le complément que vous remplacez par un pronom est un complément direct, (ex : je la vois $=$ je vois Chloé); ou un complément indirect, (ex : je lui parle $=$ je parle à Chloé).

Confirmez si les mots et les constructions que vous avez choisis existent en français. Par exemple la construction « se devenir » n'existe pas en français. Pour vérifier vos choix, utilisez un dictionnaire français/français.

Vous pouvez aussi changer la « langue » de votre Word pour éviter des fautes d'orthographe e/ou utilisez le site http://bonpatron.com/ pour vérifier des extraits qui vous semblent problématiques. 


\section{Reflexões sobre a experiência piloto}

Como uma experiência piloto, pudemos constatar que ainda há muitos pontos a serem melhorados, como, por exemplo, a necessidade de explorar mais a formulação e criação dos objetivos de pesquisa dos artigos. De qualquer forma, acreditamos que nossa experiência piloto foi positiva, por várias razões: i) do ponto de vista da professora que ministrou a disciplina, os alunos conseguiram desenvolver com sucesso o trabalho final, o que fez com que ela recomendasse a parceria no ano seguinte; ii) do ponto de vista dos alunos, eles puderam aprimorar seus textos e as notas obtidas foram globalmente satisfatórias; iii) finalmente, do ponto de vista da pesquisa e da aplicação didática, essa experiência permitiu refletir sobre como trabalhar a escrita acadêmica aliada a disciplinas ministradas na graduação, além de ter sido a primeira experiência de parceria do Laboratório de Letramento Acadêmico com disciplinas na área de Francês da FFLCH-USP.

Parece-nos também importante ressaltar a importância de ensinar os alunos a produzirem os textos que lhe são pedidos, e não apenas pedir que eles os produzam, sem dar-lhes ferramentas para tal. Guimarães-Santos afirma (2013:1) que:

Écrire est une tâche complexe qui suppose que l'on connaisse les règles d'organisation du genre de texte produit. Si les étudiants ne sont pas habitués aux genres, produire un texte adéquat sera probablement une tâche infaisable. Un piège courant dans cette situation est penser que les règles et les conventions régissant l'écriture académique font partie du « sens commun » et n'ont pas besoin d'être explicitement enseignées (Coffin et al., 2003). Bien au contraire, il est essential d'enseigner systématiquement les caractéristiques de ces genres car ce n'est pas évident pour les étudiants de les reconnaitre ni de les employer dans leurs textes.

Produire un bon texte universitaire, une tâche déjà difficile, devient encore plus compliqué quand on doit le faire dans sa deuxième langue. La non maitrise de la langue cible ajoute d'autres difficultés à la tâche déjà complexe d'écrire un texte.

Apesar do interesse da proposta, reconhecemos que o tempo disponível para a aplicação da SD foi insuficiente para explorar toda a complexidade do artigo científico. De qualquer forma, ressaltamos que, como a disciplina tinha como foco a discussão das obras de Pascal 
Quignard e não exclusivamente o aprendizado da escrita acadêmica, já era esperado que o tempo dedicado à SD fosse curto.

Além disso, poucos alunos puderam vir aos plantões de dúvidas, ou seja, justamente os momentos em que uma monitora estava disponível para ler o texto produzido e sugerir mudanças ou discutir pontos que não estivessem claros. Os atendimentos individuais visavam a apresentar estratégias de revisão ou releitura aos alunos tendo como objetivo a construção da autonomia do aluno e sua apropriação da produção textual acadêmica. Alguns alunos entraram em contato com a monitora por email, devido à impossibilidade de comparecer aos plantões, já outros, chegaram a marcar um atendimento, mas não puderam comparecer por compromissos profissionais. A pouca frequência nas consultas e atendimentos deve-se provavelmente ao fato de que os alunos não tinham adquirido o hábito de consultar o laboratório, algo que esperamos mudar no futuro. De qualquer forma, isso chama a atenção para as estratégias adotadas pelo Laboratório de Letramento Acadêmico, mostrando que se deve pensar em maneiras de chamar os alunos para os atendimentos, para que o resultado seja efetivo.

Por outro lado, na leitura dos artigos produzidos e conversas informais com a professora responsável pela disciplina, pudemos constatar que muitos dos problemas de formulação dos textos estavam baseados na inconsistência do trabalho desenvolvido pelos alunos, que não tinha as características de um artigo científico, já que os alunos tinham dificuldade em colocar-se no papel de pesquisadores, formulando uma questão de pesquisa. Ao pedir um artigo científico, a professora espera que os alunos leiam as obras do autor em questão, encontrem um ponto que os interesse e o explorem, mas o que muitas vezes ocorre é a não leitura das obras, resultando em trabalhos que não vão além do que foi apontado em sala de aula. Portanto, no futuro, é preciso ter uma preocupação com a formação de futuros pesquisadores, incentivando os alunos a proporem e discutirem ideias, como 'autores' de sua própria pesquisa.

\section{Conclusões}

Este artigo tinha por objetivos principais apresentar o modelo didático (MD) do gênero artigo científico e, em seguida, apresentar 
atividades de uma sequência didática elaborada para graduandos de um curso de Letras-francês, ligada à disciplina da área de Literatura - Monografia. O modelo didático apresentado traz uma grande contribuição aos estudos do ISD e aos estudos sobre a escrita acadêmica, em geral, pois se trata de uma das poucas iniciativas de elaboração de um MD do artigo científico em francês. A sequência didática proposta a partir desse MD também é uma contribuição do artigo, sobretudo por ter sido elaborada para um grupo de estudantes universitários que faziam uma disciplina de Literatura, já que muitas vezes não há propostas de produção de artigos científicos em parceria com outras disciplinas. Portanto, podemos dizer que a aplicação desse projeto piloto de parceria entre o Laboratório de Letramento Acadêmico e uma disciplina obrigatória da graduação nos demonstrou a importância do desenvolvimento de atividades voltadas para o ensino de gêneros acadêmicos e, também, uma possibilidade concreta de fazê-lo. Isso atesta a relevância do desenvolvimento de pesquisas na área de Letramento Acadêmico, explorando também gêneros acadêmicos em línguas estrangeiras, como o francês.

Tornar os alunos de graduação capazes de produzir artigos científicos em língua estrangeira, primeiramente potencializa a possibilidade de publicações de pesquisadores brasileiros em revistas e livros internacionais, mas, sobretudo, desenvolve nos estudantes capacidades de linguagem que podem ser mobilizadas na produção de outros textos da esfera acadêmica, tanto em língua materna como em francês. Como já apontamos, as capacidades de linguagem desenvolvidas podem ser transpostas para outras situações de comunicação e é nesse sentido que a parceria entre projetos e Laboratórios destinados à escrita acadêmica e cursos universitários é de grande importância no panorama atual de internacionalização das universidades e da pesquisa em geral.

Recebido em: 01 de outubro de 2014 Aprovado em: 01 de julho de 2015 E-mails: elianelousada@uol.com.br mariana.casemiro.barioni@gmail.com jaci.tonelli@usp.br 


\section{Referências bibliográficas}

Authier-Revuz, Jacqueline. 2001. Palavras incertas: as não coincidências do dizer. Trad. Claudia R. Castellanos Pfeiffer et al. Campinas, SP: Unicamp.

BARIONI, Mariana Casemiro. 2012. Aprendizagem da produção de gêneros textuais da esfera acadêmica na universidade: resumo e resenha. Relatório Final de Pesquisa. Universidade de São Paulo, São Paulo.

Barros, Eliana Merlin Deganutti de. 2009. O Gênero Textual como articulador entre o ensino da língua e a cultura midiática. In: Nascimento, Elvira Lopes (Org.). Gêneros Textuais: da didática das línguas aos objetos de ensino. São Carlos: Claraluz.

Beato-Canato, Ana Paula Marques. 2008. Produção escrita em língua estrangeira à luz do Interacionismo Sóciodiscursivo. In: CRISTOVÃo, Vera Lúcia Lopes (Org.). Estudos da Linguagem à Luz do Interacionismo Sóciodiscursivo. Londrina, PR: UEL.

Bronckart, Jean-Paul. 1999/2003. Atividade de Linguagem, Textos e Discurso: por um interacionismo sócio-discursivo. Trad. Anna Rachel Machado e Péricles Cunha. São Paulo: EDUC.

. 2006. Atividade de linguagem, discurso e desenvolvimento humano. Campinas, SP: Mercado de Letras.

2008. O agir nos discursos: das concepções teóricas às concepções dos trabalhadores. Campinas, SP: Mercado de Letras.

CRISTOVÃo, Vera Lúcia Lopes. 2010. Sequências didáticas para o ensino de línguas. In: CRIStovão, Vera Lúcia Lopes; DIAS, Reinildes. (Org). O livro didático de língua estrangeira: múltiplas perspectivas. Campinas, SP: Mercado de Letras.

De Pietro, Jean-François. et al. 1996/1997. Un modèle didactique du "débat": de l'objet social à la pratique scolaire. Enjeux, v. 39/40: 100-129.

Dion, Jennifer. 2012. Le défi de former une relève scientifique d'expression française. Québec : Bibliothèque des archives nationales du Québec. Disponível em: http://www.cslf.gouv.qc.ca/publications/pubf321/ f321.pdf. Acesso 30 jan. 2014.

Dolz, Joaquim; Pasquier, Auguste; Bronckart, Jean-Paul. 1993. L'acquisition des discours: émergence d'une compétence ou apprentissage de capacités langagières? Études de Linguistique Appliquée, $\mathrm{n}^{\circ}$ 92: 23-37.

Dolz, Joaquim; Gagnon, Roxane; Toulou, Simon. 2008. Production écrite et difficultés d'apprentissage. Genève: Carnets de sciences de l'éducation. 
Dolz, Joaquim. 2009. Posfácio. In: Abreu-Tardelli, Lília Santos; Cristovão, Vera Lúcia Lopes (Org). O ensino e a aprendizagem de gêneros textuais. Textos de Anna Rachel Machado e colaboradores. Campinas, SP: Mercado de Letras.

FrIEDRICH, Janette. 2012. Lev Vigotski: mediação, aprendizagem, desenvolvimento. Campinas, SP: Mercado de Letras.

Guimarães-SAntos, Luiza. 2012. O gênero itinéraire de voyage para pensar o agir social no ensino-aprendizagem do FLE. São Paulo, 260 f. Dissertação (Mestrado em Estudos Linguísticos, Tradutológicos e Literários em Francês) - Universidade de São Paulo, São Paulo. .2013. La rédaction universitaire: vers une formation en français langue seconde. Guelph, 88p. Major Paper (Master of Arts) Universidade de Guelph, Guelph.

LousADA, Eliane Gouvêa. 2002. Elaboração de material didático para o ensino do francês. In: Dionísio, Angela Paiva; MAChado, Anna Rachel; Bezerra, Maria Auxiliadora (Org.). Gêneros textuais \& Ensino. $4^{\mathrm{a}}$ ed. Rio de Janeiro: Lucerna.

2009. Produção Escrita em Francês como Segunda Língua: uma experiência baseada em gêneros textuais. In: Revista do GEL (Araraquara), v. 6: 160 -174.

2010. A abordagem do interacionismo sociodiscursivo para a análise de textos. In: Cunha, C.L.; Piris, E.L.; Carlos, J.T. (Org.). Abordagens metodológicas em estudos discursivos. São Paulo: Paulistana. Disponível em: http://www.epedusp.org/IIepedlivro/ index.htm.

Lousada, Eliane Gouvêa; Abreu-Tardelli, Lília Santos. 2010. Por que ensinar resumos na escola. In: Revista Carta fundamental, $\mathrm{n}^{\mathrm{o}} 15$, fev.: 48-51.

Lousada, Eliane Gouvêa; Rocha, Suélen Maria; GuImarãEs-Santos, Luiza. 2015. Gêneros orais, projetos didáticos de gêneros e mobilidade estudantil: perspectivas para ensinar a agir em francês como língua estrangeira. In: Bueno, Luzia; CostA-HüBes, Terezinha C. (Org.). Gêneros orais no ensino. Campinas, SP: Mercado de Letras.

Machado, Anna Rachel. 2000. Uma experiência de assessoria docente e de elaboração de material didático para o ensino de produção de textos na universidade. In: DELTA, São Paulo, vol.16 n.1: 1-26.

. 2001. Um instrumento de avaliação de material didático com bases nas capacidades de linguagem a serem desenvolvidas no aprendizado de produção textual. In: Intercâmbio, São Paulo, SP, v. 10: $137-147$. 
2002. Revisando o conceito de resumos. In: Dionísio, Angela Paiva; Machado, Anna Rachel; Bezerra, Maria Auxiliadora (Org.). Gêneros textuais \& Ensino. 4. ed. Rio de Janeiro: Lucerna.

Machado, Anna Rachel; CRISTOVÃo, Vera Lúcia Lopes. 2006. A construção de modelos didáticos de gêneros: aportes e questionamentos para o ensino de gêneros. In: Linguagem em (Dis)curso - LemD, Tubarão, v. 6, n. $3: 547-573$.

MaIngueneau, Dominique. 1991. L'analyse du discours, introduction aux lectures de l'archive. Paris: Hachette Université.

2001. Análise de textos de comunicação. Trad. Cecília P. de Souza-e-Silva; Décio Rocha. São Paulo: Cortez Editora.

MotтA-Roth, Désirée; Hendges, Graciela Rabuske. 2010. Produção textual na universidade. São Paulo: Parábola Editorial.

MülLeR, Gabrielle; GAJO, Laurent et al. 2012. Participation, ressources plurilingues et élaboration des connaissances dans l'enseignement supérieur. In : MoNDADA, Lorenza \& NussBAum, Luci (éds). Interactions cosmopolites: l'organisation de la participation plurilingue. Limoges: Editions Lambert Lucas. p. 193-223.

Petreche, Célia Regina Capellini. 2008. A sequência didática nas aulas de língua inglesa do ensino médio e o desenvolvimento das capacidades de linguagem. In: Cristovão, Vera Lúcia Lopes (Org.). Estudos da Linguagem à Luz do Interacionismo Sociodiscursivo. Londrina, PR: UEL.

Schneuwly, Bernard; Dolz, Joaquim. 1998. Pour un enseignement de l'oral-Initiation aux genres formels à l'école. Paris: ESF (Didactique du Français).

2004. Gêneros orais e escritos na escola. Campinas, SP: Mercado de Letras.

Silva, Emily Caroline da; Lousada, Eliane Gouvêa. 2014. O plano de estudos: um gênero textual acadêmico para pleitear intercâmbio. In: Revista Horizontes, vol. 32, n. 1: 73-87.

Volosinov, Valentin Nicolaevich. 1929/2010. Marxisme et philosophie du langage. Les problèmes fondamentaux de la méthode sociologique dans la science du langage. Tradução de Patrick Sériot e Inna Tylkowski- Ageeva. Limoges: Lambert Lucas.

Vigotski, Lev Semionovitch. 1997. Pensée et Langage. Paris: La Dispute.

1998. A Formação Social da Mente. São Paulo: Martins Fontes. 
33.3

2017
Regina Celi Mendes Pereira, Raquel Basílio, Poliana Dayse Vasconcelos Leitão 